\title{
Techniques of robotic radical prostatectomy for the management of prostate cancer: which one, when and why
}

\author{
Shuo Liu, Ashok Hemal \\ Department of Urology, Wake Forest Baptist Health, Winston-Salem, North Carolina, USA \\ Contributions: (I) Conception and design: All authors; (II) Administrative support: None; (III) Provision of study materials or patients: None; (IV) \\ Collection and assembly of data: None; (V) Data analysis and interpretation: None; (VI) Manuscript writing: All authors; (VII) Final approval of \\ manuscript: All authors. \\ Correspondence to: Ashok Hemal. Department of Urology, Wake Forest Baptist Health, North Carolina Medical Center Boulevard, Winston-Salem, \\ NC 27157-1094, USA. Email: ahemal@wakehealth.edu.
}

\begin{abstract}
The advent of robotic assistance in surgery has completely revolutionized the surgical management of prostate cancer. It enables precise dissection and reconstruction in order to maximize oncological and functional outcomes. In many parts of the world, robot-assisted laparoscopic radical prostatectomy has evolved to become the surgical standard of care for localized disease, including in appropriately selected patients with high risk prostate cancer. Its role has also been expanded to encompass cytoreductive prostatectomy and salvage radical prostatectomy. As surgical expertise grows with robotic assistance, several novel and non-radical approaches have been developed to further mitigate treatment side effects. Patient characteristics, disease factors and surgeon expertise are important metrics for consideration when selecting the most appropriate technique for any given patient.
\end{abstract}

Keywords: Robotic surgery; laparoscopy; radical prostatectomy; prostate cancer

Submitted Aug 18, 2019. Accepted for publication Sep 05, 2019.

doi: $10.21037 /$ tau.2019.09.13

View this article at: http://dx.doi.org/10.21037/tau.2019.09.13

\section{Introduction}

It has been almost 20 years since the first robot-assisted laparoscopic radical prostatectomy (RALRP) was performed (1). Early efforts by Menon and colleagues focused on improvising steps from open retropubic and laparoscopic radical prostatectomies (2). The ensuing decade witnessed the rapid diffusion of robotic technology in urology. RALRP has since been purported as the new "gold standard" of surgical care for localized prostate cancer (3). This period also oversaw a wide array of technical refinements to the procedure.

Today the accumulation of surgical expertise propels a plethora of exciting new techniques and concepts that extend beyond the confines of traditional radical prostatectomy. Finer instrumentation and emergence of new robotic platforms such as single port technology allow urologists to push the boundaries of minimally invasiveness and surgical feasibility. The introduction of newer imaging modalities such as multiparametric magnetic resonance imaging (mpMRI) and prostate-specific membrane antigen (PSMA) positron emission tomography (PET) also accelerate this trend as surgeons are provided with better insights into an individual's burden of disease. Together these novel developments challenge the notion of RALRP as the "one procedure fits all" and place more stringent emphasis on achieving better functional outcomes whilst ensuring oncological efficacy.

In this review, we discuss the different approaches to the surgical treatment of prostate cancer using the robotic platform, as well as the numerous recent advances and innovations that have been made.

\section{RALRP}

Techniques of standard transperitoneal RALRP have been 
extensively described in the existing literature. Numerous nonrandomized studies have reported major improvements in perioperative and long-term outcomes compared to its open and laparoscopic counterparts. Surgical experience is greatly enhanced with the availability magnified $3 \mathrm{D}$ vision, fine articulating instruments and tremor filtration. In a randomized controlled trial first published in 2016, Yaxley et al. compared the outcomes of a robotic surgeon with 200 case experience with that of an open surgeon with 1,500 case experience (4). Despite the fact that excellent oncological and functional results were achieved equally in both groups, significantly less operative time, blood loss, adverse events, length of hospital stay and postoperative pain were observed in the robotic arm.

Since the procedure was first popularized in early 2000, numerous technical modifications have been described in the literature (5). In most mature cohorts, overall positive surgical margin (PSM) rates ranged between $6.5 \%$ to $32 \%$ (9\% for pT2, range $4-23 \%$ ) (6). The apex is one of the commonest sites involved. Tewari et al. reported their method of apical dissection with 30-degree upward lens posterior to the prostate and noted a significant reduction in apical margin positivity (7). Others have found that early suture ligation of the dorsal venous complex (DVC) was associated with increase in PSM and favor the upfront coldcut transection of the DVC and the urethra (8).

It is widely recognized that maneuvers such as bladder neck preservation and subapical urethral dissection lead to earlier return of continence $(9,10)$. However, these should only be performed in suitable candidates to ensure negative margin. Other measures aimed at improving continence include various techniques of periurethral suspension and reconstruction of anterior urethral support (11-16). Posterior rhabdosphincter reconstruction or the "Rocco stitch" is routinely performed in most centers before vesicourethral anastomosis (17). Despite contradicting data about its role in early continence, it has added benefits of reducing anastomotic tension and augmenting hemostasis.

With better insights into the neuroanatomical distribution of cavernous nerves, the concept of prostatic fascia sparing technique was popularized which included the preservation of posterior neurovascular bundles and lateral fascia known as the "Veil of Aphrodite". Incremental nerve sparing (NS) has been an integral aspect of RALRP since its inception (18). Using the veins on the lateral surface of the prostate as anatomical landmarks, a grading system from 1 to 4 has also been proposed (19). Similarly, a 1 to 5 scaling system has been reported based on the location of periprostatic arterial vasculature (20). Regardless of the anatomical structure referenced, nerve preservation starts at the level of the tip and the lateral aspect of the seminal vesicle. The mantra from open radical prostatectomy era applies: cautious athermal dissection with minimal traction of the neurovascular bundles. The standard approach to NS is antegrade with the prostatic pedicle being controlled and divided prior to bundle release. It has been described that an effective technique of early release of the neurovascular bundle is at the lateral surface of the gland prior to pedicle ligation (21). This approach helps to define the bundle's path early and minimizes the chance of inadvertent injury caused by surgical clips.

\section{Intraoperative frozen section (FS) \& neurovascular structure-adjacent FS examination (NeuroSAFE)}

Intraoperative FS analysis of the prostate and/or adjacent structures has been utilized since the era of open radical prostatectomy. It helps to establish the boundaries of surgical excision and facilitate NS when possible. Methods of FS differ in terms of sites sampled (apical, basal, posterolateral or whole surface), techniques of specimen handling and histopathological analysis, and whether that the evaluation is undertaken systematically and routinely or only when there is a strong clinical suspicion for incomplete resection. It is perhaps due to this broad disparity that mixed conclusions were drawn regarding the reliability and the usefulness of FS. Its sensitivity in predicting PSM ranged widely from $21 \%$ to $96 \%$ (22).

Neurovascular structure-adjacent FS examination (NeuroSAFE) is a technique first reported in a series of 11,069 consecutive patients who had open or robotassisted prostatectomy (23). The prostate is first removed with one or both neurovascular bundles been left intact. Posterolateral aspects of the specimen are then sectioned and submitted for analysis. If one or more malignant glands were detected at the inked surface, en bloc resection of the ipsilateral neurovascular bundle and the lateral edges of pararectal fat and Denonvilliers' fascia is carried out. This method of analysis is associated with an astonishing $97.3 \%$ accuracy when compared with final pathology. Amongst the $2.5 \%$ false-negative NeuroSAFE specimens, all positive margins were deemed focal and less than $0.5 \mathrm{~mm}$ in size. In their subanalysis of those who had RALRP, NS was accomplished in $97 \%$ of those underwent NeuroSAFE (vs. $81 \%$ without, $\mathrm{P}<0.0001$ ). This was accompanied by a 
paradoxical drop in PSM (16\% with NeuroSAFE vs. 24\% without, $\mathrm{P}=0.0037)$. These improvements were particularly pronounced amongst those with high risk diseases: for example, up to $94.1 \%$ of patients with pT3a disease received NS (vs. 74.2\% without, $\mathrm{P}<0.0005)$ and the $\mathrm{R} 1$ rate dropped to $22 \%$ (from $38.7 \%, \mathrm{P}=0.0191$ ).

Similar benefits in the rates of PSM and NS were reproduced in a smaller nonrandomized comparative study (24). Twelve-month potency and pad-free continence were noted to be significantly improved. The NeuroSAFE PROOF study is a multi-institutional randomized controlled trial currently underway in the United Kingdom designed to further validate the oncological and functional benefits associated with this approach (25).

\section{Fluorescence-enhanced prostatectomy with indocyanine green (ICG)}

ICG is a near-infrared fluorescent dye that can be visualized with the built-in Firefly ${ }^{\circledR}$ technology available on most existing da Vinci surgical systems. Its small molecular weight allows it to flow freely within human vasculature and lymphatic system (26). It is important to remember that it has no particular affinity for tumor cells and its pattern of diffusion within the prostate remains incompletely understood. Early works on the use of ICG in the context of prostatectomy investigated its potential as an alternative to radioactive sentinel node dissection $(27,28)$. The tracers were injected into the prostatic tissue via the transrectal route immediately before surgery and its ability to define lymphatic drainage was studied. In a later study a more streamlined technique was developed in which unconjugated ICG was delivered intraoperatively to the prostate by transcutaneous needle after the development of the retropubic space (29). At a mean time of 10 minutes post-injection the prostate and its associated lymphatic pathways demonstrated uniform ICG uptake in comparison to the relative absence of fluorescence in the surrounding neurovascular bundles, seminal vesicles and vas deferens. At approximately 30 minutes, sentinel prostatic lymph nodes were successfully identified in 38 of $50(76 \%)$ patients. In another series of 84 patients, nodal staging based on ICGguided sentinel lymph node dissection was accurate in 82 (98\%) (30). However, only $60 \%$ of metastatic nodes were stained positive for ICG. Similar findings were reported by a separate study (31). The authors concluded that the technology in its current form can help identifying patients at risk of nodal disease but is inadequate in guiding the extent of dissection. Other studies have also examined the role of intravenously administered ICG as a useful adjunct in facilitating the identification and preservation of neurovascular bundles as well as in improving the visualization of vascular pedicles and accessory vessels (32).

\section{Augmented-reality radical prostatectomy}

Extra visual cues can be quite valuable in robotic surgery as there is a complete absence of tactile feedback for the surgeon at the console. The concept of imaging-assisted minimally invasive surgery for prostate cancer is not new (33). Most existing efforts in prostate surgery are concentrated on the manipulation of imaging data derived from real-time intraoperative transrectal and transurethral ultrasonography (33-35). The rendered images are then compiled and superimposed on the displayed field of vision. It is hoped that these technologies can provide the operator with visual "road maps", enhancing anatomical interpretation of each individual case beyond the immediate surgical view.

Porpiglia et al. recently published their pioneering work on three-dimensional elastic augmented reality when performing RALRP (36). These virtual models are constructed using images from high-resolution mpMRI. They are "elastic" and deform in response to real-time surgical traction and pressure. More importantly these virtual representations highlight the locations of index lesions as well as potential sites for extracapsular extension. The intraoperative navigation helps to minimize inadvertent PSM and maximize the preservation of neurovascular bundle where appropriate. The authors believe that the model will improve the accuracy of dissection even for highly experienced surgeons. Current limitations include over reliance on mpMRI interpretation and that the construction process is both labor and time intensive.

\section{The extraperitoneal approach}

Extraperitoneal access to the prostate is well-known to surgeons who are trained in open and pure laparoscopic radical prostatectomy (Table 1). On the robotic platform, it was shown to be a safe and feasible alternative to the transperitoneal approach (37). It has several theoretical advantages: (I) minimizing peritoneal irritation caused by blood and urine derived from the operative field; (II) it places less demand on the angle of Trendelenburg as loops of small bowel and the sigmoid colon are being contained out of the way; (III) in obese patients, shorter travel 
Table 1 Alternative techniques of robot-assisted laparoscopic radical prostatectomy

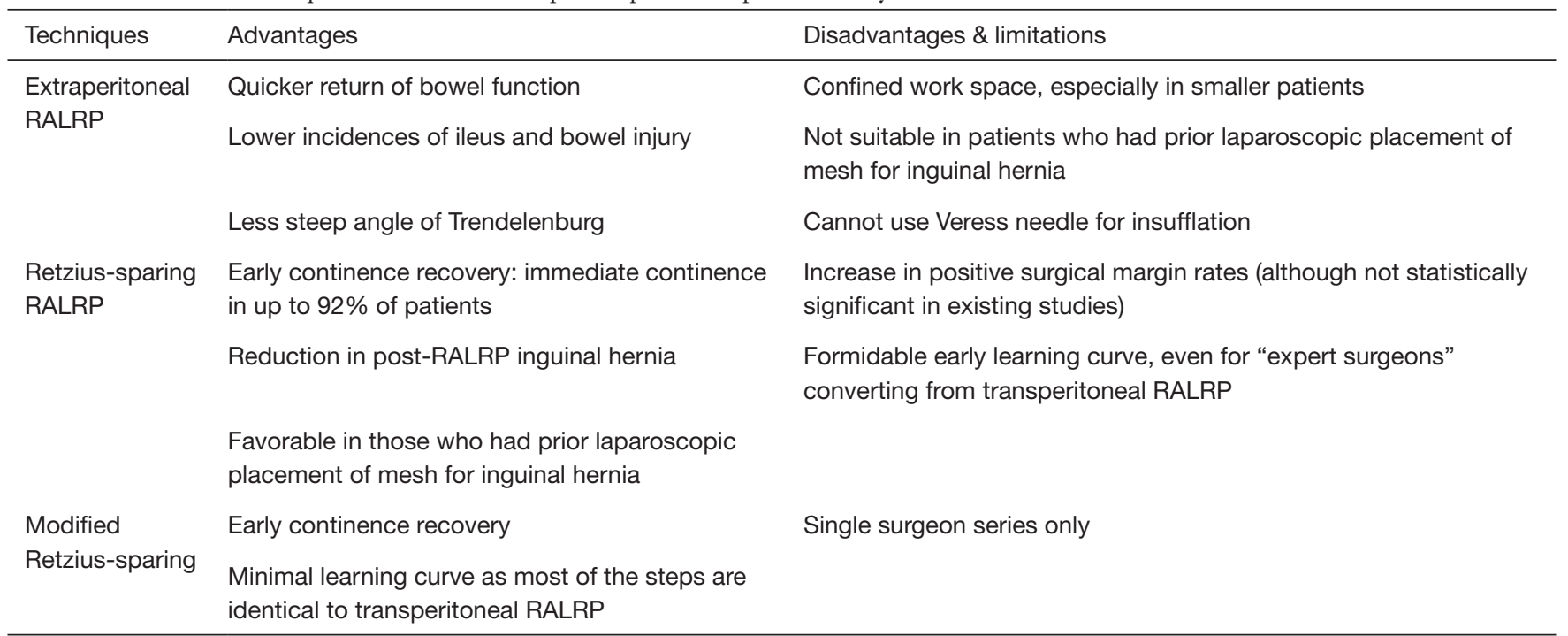

RALRP, robot-assisted laparoscopic radical prostatectomy.

distance for the robotic instruments to reach the prostate. Disadvantages include more confined working space and potential difficulties in creating the space in men who had prior laparoscopic placement of hernia mesh.

An infraumbilical incision is made to create the preperitoneal space. Blunt finger dissection of the space is undertaken to permit the introduction of a balloon dilator. Gas insufflation and port placements are carried out under direct vision. The port configuration resembles that of the transperitoneal approach although distances between trocars can be as short as $4 \mathrm{~cm}$ in smaller men (38). The rest of the procedure follows identical steps to that of the transperitoneal approach.

Studies comparing the two methods of access fail to detect significant differences in most perioperative and oncological outcomes (38-42). Some series report fewer incidences of ileus and bowel injury as well as earlier normalization of gastrointestinal function with the extraperitoneal access $(40,41)$. There was no documented increase in the rates of lymphocoele following pelvic lymph node dissection (42). A small nonrandomized prospective study also reported drop in ventilatory pressure requirement during the case due to reductions in the angle of Trendelenburg and the degree of abdominal distension (40). A recently published single surgeon experience of 1,168 cases further supports the safety and efficacy of the extraperitoneal approach, including in men with large glands (39).

\section{Retzius-sparing (RS-RALRP)}

The Retzius-sparing approach was first described by Bocciardi and colleagues in 2013 with immediate continence observed in up to $92 \%$ of the patients (43). This benefit in continence recovery was corroborated by multiple subsequent publications including two randomized controlled trials. Comparative studies to standard RALRP have demonstrated up to $47 \%$ increase in immediate continence with median time to continence as low as 1 to 2 days following catheter removal (44-48). However, the observed differences in urinary function between the two approaches do diminish over time with the rates of continence starting to equalize at 3 to 6 months in most series (49).

Contrary to the standard approach starting with the development of the retropubic space, a transverse incision is first made at the peritoneal reflection underlying the rectovesical pouch. Seminal vesicles and vas deferens are then identified and mobilized to the specimen. Antegrade dissection starts at the posterior and posterolateral surfaces of the prostate and the neurovascular bundles are swept laterally. The bladder neck is divided in a posterior to anterior direction. Anteriorly the DVC is separated from the prostate using sharp dissection, sparing the puboprostatic fibromuscular tissue and minimizing anatomical disturbances to all structures above the endopelvic fascia. The urethra is transected below the prostatic apex and the specimen is freed. The vesicourethral anastomosis starts 
at twelve o'clock (as opposed to six o'clock). No posterior reconstruction is required.

The exact mechanisms leading to faster urinary recovery remain a cause for speculation. During a RS-RALRP there is minimal mobilization around the bladder and most of the structures adjacent to the membranous urethra have been left intact. One recent study confirmed that the bladder neck assumes a more anatomical position following RSRALRP (46).

Other less studied benefits might include shorter operative time, reduction in the incidences of post-RALRP inguinal hernia and perhaps quicker recovery of erectile function $(43,48,50,51)$. The approach is also advantageous in those who had laparoscopic mesh placement for inguinal hernia, obviating the need for adhesiolysis and the risk of inadvertent bladder injury.

The main reservation about the wider adoption of this technique is whether long-term oncological outcomes are being compromised for transient improvement in urinary function. Existing studies have consistently reported higher PSM rates associated with RS-RALRP $(48,49)$. It is also worthwhile noting that most of the published experiences are concentrate in the hands of "expert" surgeons from high volume centers in radical prostatectomy. The trend however does appear to ameliorate over time as individual surgeons become more familiar with the approach: Galfano et al. reported reduction in T2 PSM rates from 22\% to $9 \%$ $(\mathrm{P}=0.045)$ after the first hundred cases were performed at their institution, Lim et al. observed similar phenomenon after their initial 25 cases $(20 \%$ to $8 \%, \mathrm{P}=0.417)(43,47)$. Unsurprisingly, several authors also noted increases in the proportion of anterior PSM $(45,47)$. Overall a recent systemic review found that PSM rates are significantly higher in RS-RALRP (24\% vs. 15.2\%, $\mathrm{P}=0.01$ ). Despite concerns regarding margin safety, none of the existing comparative series reported significant difference in shortterm biochemical recurrence (49). A recent analysis of 359 patients who had RS-RALRP reported overall 3-year biochemical free survival at $80.9 \%$ and $72 \%$ in those with high- or very-high-risk diseases (52). This is comparable to the medium-term outcomes from published series on standard RALRP. Longer term oncological data are lacking.

\section{Modified Retzius-sparing technique}

Whilst the Retzius-sparing technique delivers superior outcome in terms of initial continence recovery, it is technically challenging. The early learning curve can be formidable even for surgeons highly experienced in the standard robotic prostatectomy (43). A number of modified techniques have been described. The goal is to maximize the preservation of peri-urethral complex and supportive structures with the majority of the procedure being conducted in a manner that is familiar to most urologists. An example of such is the modified anterior Retzius-sparing (53). Single surgeon series has demonstrated immediate continence rate of up to $75 \%$ (vs. $25 \%$ standard) following catheter removal with no significant increase in overall PSM rate.

In this approach, bilateral incisions are made on the peritoneal covering lateral to the umbilical ligament as seen during conventional RALRP. The midline urachal ligament is however preserved thus leaving the bladder in its orthotopic position. Robotic instruments are then introduced into the inferior part of the space of the Retzius via the two lateral peritoneal windows created. Prostatectomy and subsequent reconstruction are continued in a similar fashion to the traditional robotic approach. Emphasis is placed on the preservation of the periurethral complex including the puboprostatic ligament. The anterior detrusor apron and DVC are sharply dissected off the anterior surface of the prostate if permissible by disease location and volume.

\section{Robotic perineal radical prostatectomy}

Open perineal radical prostatectomy is associated with excellent oncological outcome as well as low intraoperative morbidity and rapid convalescence (Table 2) (54). In the era of open surgery, it was ideal for obese men with small prostates given the short skin to organ distance or for those who had extensive prior abdominal surgeries. Its diffusion was however hampered by issues of surgical ergonomics due to confined vision and operative space. With the introduction of finer robotic instruments, two recent series have shown that the procedure can be safely and effectively carried out with robotic assistance $(55,56)$. Many of the limitations associated with the open procedure can be overcome with finer instrumentation, visual magnification and air insufflation of the operative field.

This new approach offers true minimal invasiveness via a single perineal incision. The initial open dissection was performed using the Belt's approach up to the prostatic apex. The GelPort is then placed and the robotic trocars are placed through the silicone seal cap in a diamondshaped configuration. This allows for the triangulation of 
Table 2 Emerging techniques currently under investigation

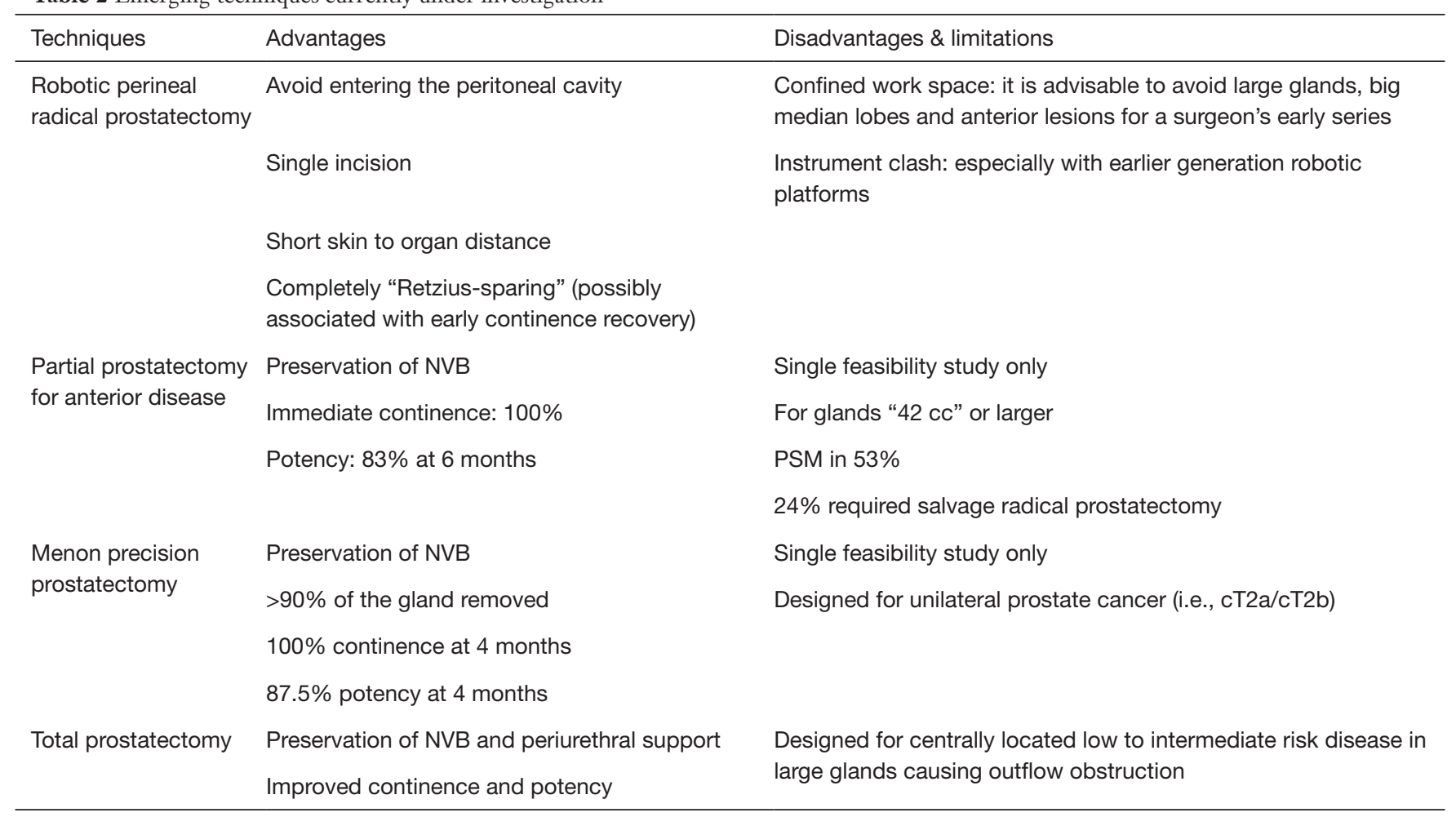

NVB, neurovascular bundle; PSM, prostate-specific membrane antigen.

the 30-degree robotic camera with its two instrument arms, as well as an assistant port at six o'clock. The prostatectomy starts posteriorly in a retrograde fashion to the seminal vesicles and vas deferens. After the division of membranous urethra, the anterior dissection proceeds underneath the DVC. Nerve preservation can be performed bilaterally and complete sparing of the Retzius space is achieved. After the division of the bladder neck, the specimen is removed. Pelvic lymph node dissection can be undertaken at this point if required by exposing the lateral perivesical space after sharply incising the endopelvic fascia. Vesicourethral anastomosis is then performed with two running V-Loc sutures over a urethral catheter.

Important points of consideration in patient selection for a surgeon's early experience should include the gland size, the presence of median lobe, the location of index lesions, as well as the likelihood of extraprostatic disease based on pre-operative mpMRI and biopsy. No major intraoperative complication was encountered in early series $(55,56)$. One case was converted to open due to carbon dioxide retention. Short hospital stay and good pain control were observed. In a retrospective matched-pair analysis of the perineal versus the standard approach, PSM rates were comparable (10\% vs. $12.5 \%$ respectively for $\mathrm{T} 2$ disease, $\mathrm{P}=0.65)$ (57). Improved urinary function and potency were noted in the perineal arm at 3, 6 and 9-month follow-ups.

\section{Radical prostatectomy in patients with kidney transplant, inflatable penile prosthesis and artificial urinary sphincter}

The pelvic location of most transplanted kidneys and reservoirs for inflatable devices such as 3-piece penile prosthesis and artificial urinary sphincter, presents unique challenges to the surgical management of newly diagnosed localized prostate cancer. However even for surgeons with no experience in the aforementioned Retzius-sparing techniques, RALRP is still technically feasible (Table 3). Recent publications have focused on the importance of port placement for its successful implementation (58).

The patient can be tilted slightly towards the side of the allograft or reservoir, lifting the contralateral side. The camera port is placed $5 \mathrm{~cm}$ above the umbilicus and only one robotic instrument is deployed on the graft side 
Table 3 Special considerations in uncommon scenarios

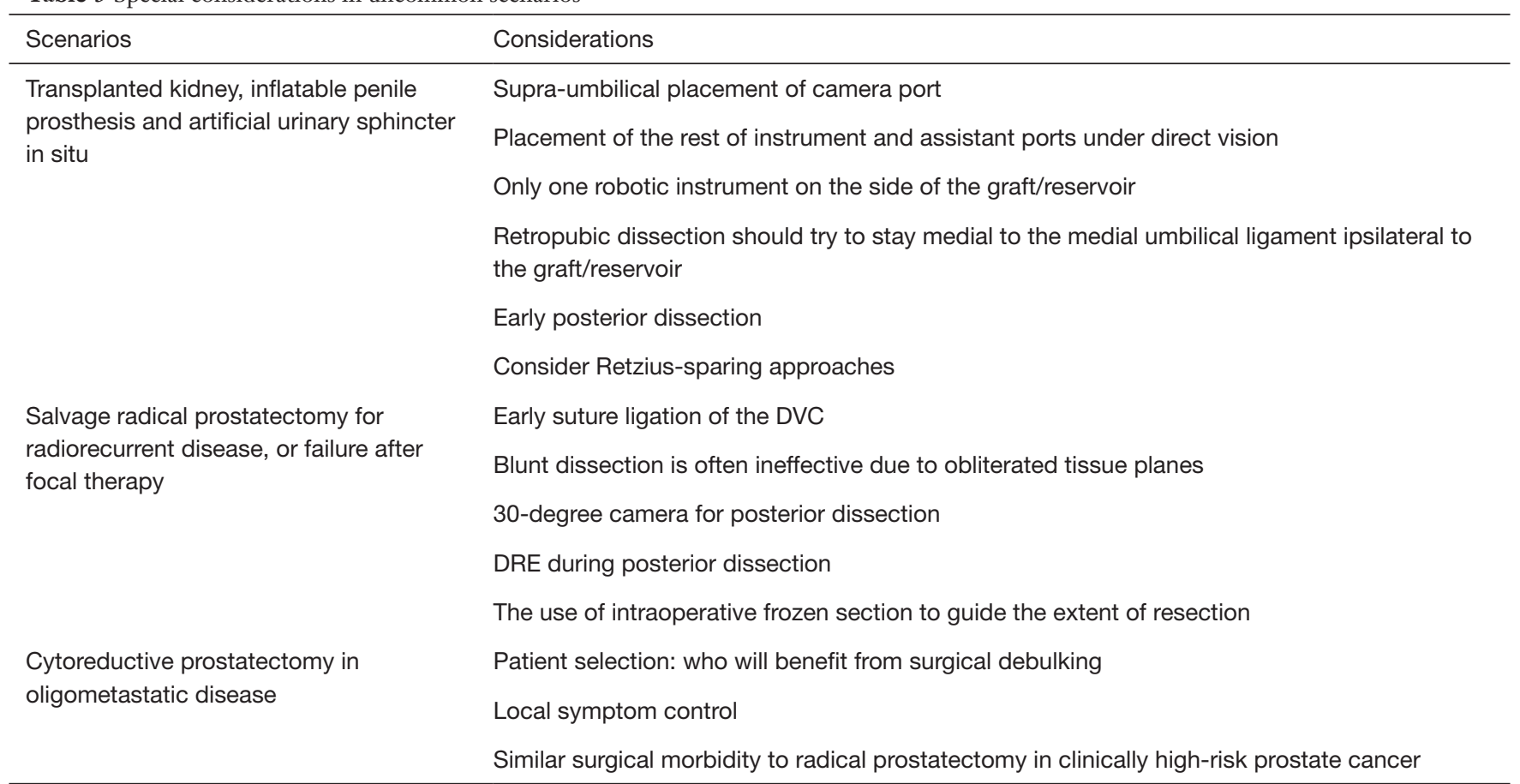

DVC, dorsal venous complex; DRE, digital rectal examination.

under direct vision. The location of the assistant port can be determined once the intraabdominal view has been established: we usually place this on the contralateral side. The configuration is thought to decrease the risk of inadvertent injury to the allograft or the implants from the passage of instruments. Full bladder mobilization is often not feasible in this setting and dissection generally stays medial to the ipsilateral medial umbilical ligament. In the case of insufficient Retzius space, posterior dissection of the seminal vesicles can be undertaken first (the Montsouris approach).

\section{Partial prostatectomy for anterior disease}

Anterior prostate cancer represents 19\% of the index lesions detected on mpMRI with the majority involving the midgland and the apex $(59,60)$. There is currently insufficient data on the efficacy of focal ablative therapy in this setting (61). However, given the anatomical proximity to sensitive and functionally important structures such as the striated sphincter and the neurovascular bundle near the apex, there are genuine concerns regarding the degree of precision that can be achieved with existing ablative technologies $(61,62)$. In addition, in larger glands, access to these tumors can be difficult via the transperineal route.

Villers et al. described their novel approach in a single-arm pilot study consisted of 17 men with low to intermediate risk anterior diseases (62). Stringent inclusion and exclusion criteria were applied following routine mpMRI, MR-targeted and systematic transrectal biopsies. The anterior fibromuscular stroma, anterior bladder neck, prostate adenoma and the anterior portion of distal prostatic urethra were removed en bloc. Intraprostatic dissection was guided anteriorly by a series of anatomical landmarks and posteriorly by following the typical enucleation plane between the prostatic adenoma and the peripheral zone. The remaining anterior bladder flap was then sutured anteriorly onto the membranous urethra and laterally to the residual peripheral zones of the prostate to create a watertight anastomosis. There was no Clavien-Dindo grade 3 and above complications. Mean blood loss was less than $300 \mathrm{~mL}$.

Excellent functional outcomes were observed: all remained continent following catheter removal. Amongst those who were potent pre-operatively, $83 \%$ (10 of 12) reported potency at 6 months. However, $9(53 \%)$ had PSM including 6 who had pT3 disease. The authors concluded that the ideal gland size should be above $42 \mathrm{~mL}$ 
in order to achieve adequate excision. During the median follow-up period of 30 months, 4 required salvage radical prostatectomy (sRP) which was deemed technically "difficult" due to the small size of residual glands.

\section{Precision prostatectomy}

Other non-radical surgical techniques are under investigation for low to intermediate risk disease in an attempt to prevent surgical overtreatment. Precision prostatectomy was studied by Abdollah and colleagues in men with unilateral disease demonstrated on imaging and biopsy (63). The majority of the gland was excised and the prostatic capsule and seminal vesicle contralateral to the location of the index lesion were being left intact. It is postulated that this is an oncologically safer approach than focal therapy as over $90 \%$ of the gland is removed. At 4 months follow-up, 100\% continence recovery and $87.5 \%$ potency were observed.

\section{Robotic total prostatectomy}

We have recently evaluated the effectiveness of robotic total prostatectomy in tackling low grade centrally located tumors in men with large glands and pronounced lower urinary tract symptoms (64). In this surgical approach, the bladder neck is opened anteriorly as during the standard antegrade transperitoneal approach. The subfascial plane is developed immediately anterior to the musculofascial tissue covering of the ampullae of vas deferens and seminal vesicles. Subfascial dissection is then carried out circumferentially along the outer stromal edge of the prostate parenchyma. If a large median lobe is present then stay sutures can be placed to facilitate the identification of posterior bladder neck. Urethral transection is performed at the apex of the prostate in order to maximize urethral length. This is followed by continuous vesicourethral anastomosis. At the conclusion of the procedure, the puboprostatic ligaments, the seminal vesicles and the bilateral neurovascular bundles are spared in their entirety.

\section{SRP}

sRP is an underutilized option for the management of local recurrence following radiation or focal therapy. Historically it has been associated with high toxicity and poor functional outcomes (65). Recent studies have shown that, in appropriately selected patients, durable oncological outcomes can be achieved with low morbidity and satisfactory continence recovery $(66,67)$. In their report of 404 men following open sRP, Chade et al. found that the 10-year biochemical recurrence-free, metastasis-free and disease-specific survivals were at $37 \%, 77 \%$ and $83 \%$ respectively (68).

A recently published multi-institutional study comprised of 395 men compared the outcomes of salvage robot-assisted and open radical prostatectomy in the contemporary era: the former was associated with lower blood loss, rate of transfusion and length of hospital stay (67). The overall incidences of rectal injury were low $(0.48 \%$ robotic $v s .2 .96 \%$ open, $\mathrm{P}=0.0934)$. Anastomotic stricture was significantly less common following a robotic sRP $(8.88 \%$ vs. $18.66 \%$, $\mathrm{P}=0.0069)$. In terms of functional outcomes, men in the robotic arm was associated with lower probability of moderate to severe incontinence [odds ratio (OR) 0.411, 95\% CI: $0.232-0.727, \mathrm{P}=0.022]$ but no significant difference in potency was recorded (69). Overall, $15.6 \%$ of preoperatively potent men were able to attain erection either spontaneously or with the help of oral phosphodiesterase inhibitor. In a separate single surgeon series of 80 robotassisted cases, $0-2$ pad usage was observed in $77.7 \%$ of men and $16.6 \%$ were potent at 12 months (although only $31.2 \%$ were potent preoperatively). The study demonstrated that nerve-sparing can be attempted in selected individuals without compromising oncological outcomes.

Most of the technical challenges of sRP stem from the obliteration of anatomical planes. Blunt dissection is often ineffective in areas affected by prior treatment and scarring. Many common visual cues are also altered. Unexpected and troublesome bleeding can occur when incising the endopelvic fascia as periprostatic veins and levator muscle fibers can be densely adherent to the prostatic capsule. We recommend early suture ligation of the DVC to permit meticulous apical dissection and the maximization of urethral length. The development of the posterior plane should be undertaken with caution as the cushion of prerectal fat is frequently replaced by desmoplastic reaction and the rectum can be tented up with the anterior displacement of the prostate. The use of 30-degree camera and bedside digital rectal examination can be invaluable in avoiding rectal injury. At the time of dividing the urethra, a urethral sound can be inserted to guide apical dissection. The anastomosis should be performed with gentle tissue handling and precise suturing in order to minimize further trauma to the tissues thus reducing the risk of anastomotic stricture down the track. 
Despite the growing body of level 2 evidence supporting its safety and oncological effectiveness, several major challenges remain in terms of its wider uptake. The current ASTRO Phoenix definition of treatment failure means that in the majority of cases the search for disease recurrence is not triggered until a PSA rise of $2 \mathrm{ng} / \mathrm{mL}$ above the nadir value has been reached. The clinical uncertainty surrounding whether that the recurrence is local or systemic can further delay or restrict surgical referrals. The less than desirable functional outcomes following sRP also prompt the investigation of salvage focal therapies as potential alternatives (70).

\section{Cytoreductive prostatectomy in oligometastatic disease}

Systemic therapy such as androgen deprivation treatment (ADT) has traditionally been the mainstay of treatment for all cases of metastatic prostate cancer regardless of differences in disease burden and prognosis. Recent studies however have suggested that oligometastatic disease might represent a biologically and clinically more distinct state than previously thought. A subset of patients might benefit from local therapy in the form of cytoreductive prostatectomy or radiotherapy. In addition, the introduction of newer imaging modalities such as PSMA PET allows the diagnosis of systemic disease to be made at an earlier stage.

Theoretical benefits of local therapy include: (I) reducing overall burden of disease; (II) curtailing further tumor cell dissemination and (III) stopping cytokine release from the prostate gland which might play an active role in furthering carcinomatosis and also serve as a "sanctuary site" for cancer cells (71). A more aggressive approach also significantly reduces long-term local symptoms such as hematuria, hydronephrosis and bladder outlet obstructions. In a SEERbased analysis of 13,692 patients between 2004 and 2013, it was observed that local therapy resulted in significantly lower disease-specific mortality when compared to systemic therapy alone [hazard ratio (HR) $0.40,95 \%$ CI: 0.32-0.50, $\mathrm{P}<0.001]$ (72). During subanalysis cytoreductive prostatectomy (HR 0.35, 95\% CI: $0.35-0.46, \mathrm{P}<0.001$ ) was found superior to radiotherapy (HR $0.48,95 \%$ CI: $0.35-0.66, \mathrm{P}<0.001)(72)$. Other retrospective series have also demonstrated that surgery is associated with improved progression-free (PFS), disease-specific (DSS) and overall survivals, as well as longer time to castration resistance (7377). However major selection bias might have contributed to these results. These studies have also found that cytoreductive prostatectomy is generally well tolerated and has similar safety profile to that of radical prostatectomy for high risk localized disease.

In a review of 38 men treated with robot-assisted cytoreductive prostatectomy: median operating time was 147 [35-186] minutes and estimated blood loss was 300 [200-500] mL (75). Only 2 Clavien-Dindo grade 3 and above complications were encountered. During the follow up period, none of the post-surgical patients had any urinary complication whilst $26.8 \%$ of non-surgical patients (ADT alone) required operative intervention for issues pertaining to local disease progression. DFS and DSS were markedly prolonged in the surgical arm (median PFS 75 vs. 28 months ADT alone, $\mathrm{P}=0.008$; DSS not reached vs. 40 months ADT alone, $\mathrm{P}=0.002$ ).

There are currently three active randomized trials (SWOG S1802, g-RAMMP and TRoMbone) aiming to better define the role of cytoreductive prostatectomy in the current era. It remains to be seen whether this treatment modality will gain traction over time.

\section{Conclusions}

There is a paradigm shift in the surgical management of prostate cancer with the development of robot-assisted laparoscopic surgery. Open and laparoscopic radical prostatectomies are being performed in increasingly limited numbers. Newer imaging tools that provide intraoperative navigation via enhanced surgical visualization or real-time histological feedback are being studied. Several approaches and modifications have been described to further minimize postoperative functional deficits and quicken recovery. Better localization of cancerous lesions within the prostate also led to the investigations of non-radical techniques such as partial, precision and total prostatectomies as viable alternatives to focal therapy. In addition, as surgical toxicity decreases, there are renewed interests in salvage and cytoreductive prostatectomies in patients with advanced disease.

\section{Acknowledgments}

Funding: None.

\section{Footnote}

Provenance and Peer Review: This article was commissioned by the Guest Editor (Ashok K. Hemal) for the series 
"Robotic-assisted Urologic Surgery" published in Translational Andrology and Urology. The article was sent for external peer review organized by the Guest Editor and the editorial office.

Conflicts of Interest: All authors have completed the ICMJE uniform disclosure form (available at http://dx.doi. org/10.21037/tau.2019.09.13). The series "Robotic-assisted Urologic Surgery" was commissioned by the editorial office without any funding or sponsorship. AH served as the unpaid Guest Editor of the series and serves as the unpaid editorial board member of Translational Andrology and Urology from May 2019 to Apr 2021. SL has no other conflicts of interest to declare.

Ethical Statement: The authors are accountable for all aspects of the work in ensuring that questions related to the accuracy or integrity of any part of the work are appropriately investigated and resolved.

Open Access Statement: This is an Open Access article distributed in accordance with the Creative Commons Attribution-NonCommercial-NoDerivs 4.0 International License (CC BY-NC-ND 4.0), which permits the noncommercial replication and distribution of the article with the strict proviso that no changes or edits are made and the original work is properly cited (including links to both the formal publication through the relevant DOI and the license). See: https://creativecommons.org/licenses/by-nc-nd/4.0/.

\section{References}

1. Abbou CC, Hoznek A, Salomon L, et al. Laparoscopic radical prostatectomy with a remote controlled robot. J Urol 2001;165:1964-6.

2. Menon M, Shrivastava A, Tewari A, et al. Laparoscopic and Robot Assisted Radical Prostatectomy: Establishment of a Structured Program and Preliminary Analysis of Outcomes. J Urol 2002;168:945-9.

3. Sood A, Jeong W, Peabody JO, et al. Robot-assisted radical prostatectomy: inching toward gold standard. Urol Clin North Am 2014;41:473-84.

4. Yaxley JW, Coughlin GD, Chambers SK, et al. Robotassisted laparoscopic prostatectomy versus open radical retropubic prostatectomy: early outcomes from a randomised controlled phase 3 study. Lancet 2016;388:1057-66.

5. Menon M, Hemal AK, VIP Team. Vattikuti Institute
Prostatectomy: A Technique of Robotic Radical Prostatectomy: Experience in More than 1000 Cases. J Endourol 2004;18:611-9.

6. Yossepowitch O, Briganti A, Eastham JA, et al. Positive surgical margins after radical prostatectomy: a systematic review and contemporary update. Eur Urol 2014;65:303-13.

7. Tewari AK, Srivastava A, Mudaliar K, et al. Anatomical retro-apical technique of synchronous (posterior and anterior) urethral transection: a novel approach for ameliorating apical margin positivity during robotic radical prostatectomy. BJU Int 2010;106:1364-73.

8. Guru KA, Perlmutter AE, Sheldon MJ, et al. Apical margins after robot-assisted radical prostatectomy: does technique matter? J Endourol 2009;23:123-7.

9. Selli C, Antoni P De, Moro U, et al. Role of bladder neck preservation in urinary continence following radical retropubic prostatectomy. Scand J Urol Nephrol 2004;38:32-7.

10. Deliveliotis C, Protogerou V, Alargof E, et al. Radical prostatectomy: bladder neck preservation and puboprostatic ligament sparing-effects on continence and positive margins. Urology 2002;60:855-8.

11. Patel VR, Coelho RF, Palmer KJ, et al. Periurethral Suspension Stitch During Robot-Assisted Laparoscopic Radical Prostatectomy: Description of the Technique and Continence Outcomes. Eur Urol 2009;56:472-8.

12. Campenni MA, Harmon JD, Ginsberg PC, et al. Improved Continence after Radical Retropubic Prostatectomy Using Two Pubo-Urethral Suspension Stitches. Urol Int 2002;68:109-12.

13. Noguchi M, Kakuma T, Suekane S, et al. A randomized clinical trial of suspension technique for improving early recovery of urinary continence after radical retropubic prostatectomy. BJU Int 2008;102:958-63.

14. Jorion JL. Rectus Fascial Sling Suspension of the Vesicourethral Anastomosis After Radical Prostatectomy. J Urol 1997;157:926-8.

15. Tewari AK, Bigelow K, Rao S, et al. Anatomic Restoration Technique of Continence Mechanism and Preservation of Puboprostatic Collar: A Novel Modification to Achieve Early Urinary Continence in Men Undergoing Robotic Prostatectomy. Urology 2007;69:726-31.

16. Nguyen HG, Punnen S, Cowan JE, et al. A Randomized Study of Intraoperative Autologous Retropubic Urethral Sling on Urinary Control after Robotic Assisted Radical Prostatectomy. J Urol 2017;197:369-75.

17. Rocco B, Gregori A, Stener S, et al. Posterior 
Reconstruction of the Rhabdosphincter Allows a Rapid Recovery of Continence after Transperitoneal Videolaparoscopic Radical Prostatectomy. Eur Urol 2007;51:996-1003.

18. Menon M, Kaul S, Bhandari A, et al. Potency following robotic radical prostatectomy: a questionnaire based analysis of outcomes after conventional nerve sparing and prostatic fascia sparing techniques. J Urol 2005;174:2291-6, discussion 2296.

19. Tewari AK, Patel ND, Leung RA, et al. Visual cues as a surrogate for tactile feedback during robotic-assisted laparoscopic prostatectomy: posterolateral margin rates in 1340 consecutive patients. BJU Int 2010;106:528-36.

20. Schatloff O, Chauhan S, Sivaraman A, et al. Anatomic Grading of Nerve Sparing During Robot-Assisted Radical Prostatectomy. Eur Urol 2012;61:796-802.

21. Coughlin G, Dangle PP, Palmer KJ, et al. Athermal early retrograde release of the neurovascular bundle during nerve-sparing robotic-assisted laparoscopic radical prostatectomy. J Robot Surg 2009;3:13-7.

22. Nunez AL, Giannico GA, Mukhtar F, et al. Frozen section evaluation of margins in radical prostatectomy specimens: A contemporary study and literature review. Ann Diagn Pathol 2016;24:11-8.

23. Schlomm T, Tennstedt P, Huxhold C, et al. Neurovascular structure-adjacent frozen-section examination (NeuroSAFE) increases nerve-sparing frequency and reduces positive surgical margins in open and robot-assisted laparoscopic radical prostatectomy: experience after 11,069 consecutive patients. Eur Urol 2012;62:333-40.

24. Mirmilstein G, Rai BP, Gbolahan O, et al. The neurovascular structure-adjacent frozen-section examination (NeuroSAFE) approach to nerve sparing in robot-assisted laparoscopic radical prostatectomy in a British setting - a prospective observational comparative study. BJU Int 2018;121:854-62.

25. Dinneen E, Haider A, Allen C, et al. NeuroSAFE robotassisted laparoscopic prostatectomy versus standard robot-assisted laparoscopic prostatectomy for men with localised prostate cancer (NeuroSAFE PROOF): protocol for a randomised controlled feasibility study. BMJ Open 2019;9:e028132.

26. Pathak RA, Hemal AK. Intraoperative ICG-fluorescence imaging for robotic-assisted urologic surgery: current status and review of literature. Int Urol Nephrol 2019;51:765-71.

27. Jeschke S, Lusuardi L, Myatt A, et al. Visualisation of the
Lymph Node Pathway in Real Time by Laparoscopic Radioisotope- and Fluorescence-guided Sentinel Lymph Node Dissection in Prostate Cancer Staging. Urology 2012;80:1080-6.

28. van der Poel HG, Buckle T, Brouwer OR, et al. Intraoperative Laparoscopic Fluorescence Guidance to the Sentinel Lymph Node in Prostate Cancer Patients: Clinical Proof of Concept of an Integrated Functional Imaging Approach Using a Multimodal Tracer. Eur Urol 2011;60:826-33.

29. Manny TB, Patel M, Hemal AK. Fluorescenceenhanced robotic radical prostatectomy using realtime lymphangiography and tissue marking with percutaneous injection of unconjugated indocyanine green: The initial clinical experience in 50 patients. Eur Urol 2014;65:1162-8.

30. Ramírez-Backhaus M, Mira Moreno A, Gómez Ferrer A, et al. Indocyanine Green Guided Pelvic Lymph Node Dissection: An Efficient Technique to Classify the Lymph Node Status of Patients with Prostate Cancer Who Underwent Radical Prostatectomy. J Urol 2016;196:1429-35.

31. Nguyen DP, Huber PM, Metzger TA, et al. A Specific Mapping Study Using Fluorescence Sentinel Lymph Node Detection in Patients with Intermediate- and High-risk Prostate Cancer Undergoing Extended Pelvic Lymph Node Dissection. Eur Urol 2016;70:734-7.

32. Mangano MS, De Gobbi A, Beniamin F, et al. Robotassisted nerve-sparing radical prostatectomy using nearinfrared fluorescence technology and indocyanine green: initial experience. Urologia 2018;85:29-31.

33. Ukimura O, Gill IS. Imaging-Assisted Endoscopic Surgery: Cleveland Clinic Experience. J Endourol 2008;22:803-10.

34. Mohareri O, Ischia J, Black PC, et al. Intraoperative Registered Transrectal Ultrasound Guidance for RobotAssisted Laparoscopic Radical Prostatectomy. J Urol 2015;193:302-12.

35. Hung AJ, Abreu AL, Shoji S, et al. Robotic transrectal ultrasonography during robot-assisted radical prostatectomy. Eur Urol 2012;62:341-8.

36. Porpiglia F, Checcucci E, Amparore D, et al. Threedimensional Elastic Augmented-reality Robot-assisted Radical Prostatectomy Using Hyperaccuracy Threedimensional Reconstruction Technology: A Step Further in the Identification of Capsular Involvement. Eur Urol 2019;76:505-14.

37. Joseph JV, Rosenbaum R, Madeb R, et al. Robotic extraperitoneal radical prostatectomy: an alternative 
approach. J Urol 2006;175:945-50; discussion 951.

38. Kurokawa S, Umemoto Y, Mizuno K, et al. New steps of robot-assisted radical prostatectomy using the extraperitoneal approach: a propensity-score matched comparison between extraperitoneal and transperitoneal approach in Japanese patients. BMC Urol 2017;17:106.

39. Kim MS, Jang WS, Chung DY, et al. Effect of prostate gland weight on the surgical and oncological outcomes of extraperitoneal robot-assisted radical prostatectomy. BMC Urol 2019;19:1-6.

40. Ragavan N, Dholakia K, Ramesh M, et al. Extraperitoneal vs. transperitoneal robot-assisted laparoscopic radical prostatectomy - analysis of perioperative outcomes, a single surgeon's experience. J Robot Surg 2019;13:275-81.

41. Horovitz D, Feng C, Messing EM, et al. Extraperitoneal vs Transperitoneal Robot-Assisted Radical Prostatectomy in the Setting of Prior Abdominal or Pelvic Surgery. J Endourol 2017;31:366-73.

42. Lee JY, Diaz RR, Cho KS, et al. Lymphocele after extraperitoneal robot-assisted radical prostatectomy: A propensity score-matching study. Int J Urol 2013;20:1169-76.

43. Galfano A, Di Trapani D, Sozzi F, et al. Beyond the Learning Curve of the Retzius-sparing Approach for Robot-assisted Laparoscopic Radical Prostatectomy: Oncologic and Functional Results of the First 200 Patients with $\geq 1$ Year of Follow-up. Eur Urol 2013;64:974-80.

44. Dalela D, Jeong W, Prasad MA, et al. A Pragmatic Randomized Controlled Trial Examining the Impact of the Retzius-sparing Approach on Early Urinary Continence Recovery After Robot-assisted Radical Prostatectomy. Eur Urol 2017;72:677-85.

45. Eden CG, Moschonas D, Soares R. Urinary continence four weeks following Retzius-sparing robotic radical prostatectomy: The UK experience. J Clin Urol 2018;11:15-20.

46. Chang LW, Hung SC, Hu JC, et al. Retzius-sparing Robotic-assisted Radical Prostatectomy Associated with Less Bladder Neck Descent and Better Early Continence Outcome. Anticancer Res 2018;38:345-51.

47. Lim SK, Kim KH, Shin TY, et al. Retzius-sparing robotassisted laparoscopic radical prostatectomy: Combining the best of retropubic and perineal approaches. BJU Int 2014;114:236-44.

48. Checcucci E, Veccia A, Fiori C, et al. Retzius-sparing robot-assisted radical prostatectomy vs the standard approach: a systematic review and analysis of comparative outcomes. BJU Int 2020;125:8-16.
49. Phukan C, Mclean A, Nambiar A, et al. Retzius sparing robotic assisted radical prostatectomy vs. conventional robotic assisted radical prostatectomy: a systematic review and meta-analysis. World J Urol 2019. [Epub ahead of print].

50. Menon M, Dalela D, Jamil M, et al. Functional Recovery, Oncologic Outcomes and Postoperative Complications after Robot-Assisted Radical Prostatectomy: An EvidenceBased Analysis Comparing the Retzius Sparing and Standard Approaches. J Urol 2018;199:1210-7.

51. Chang KD, Abdel Raheem A, Santok GDR, et al. Anatomical Retzius-space preservation is associated with lower incidence of postoperative inguinal hernia development after robot-assisted radical prostatectomy. Hernia 2017;21:555-61.

52. Abdel Raheem A, Chang KD, Alenzi MJ, et al. Predictors of biochemical recurrence after Retzius-sparing robotassisted radical prostatectomy: Analysis of 359 cases with a median follow-up period of 26 months. Int J Urol 2018;25:1006-14.

53. Noel J, Jallad S, Liu M, et al. V11-10 Anterior Retzius Sparing Technique For Robotic Assisted Radical Prostatectomy. J Urol 2019;201:e1120-1.

54. Iselin CE, Robertson JE, Paulson DF. Radical perineal prostatectomy: Oncological outcome during a 20-year period. J Urol 1999;161:163-8.

55. Tŭğcu V, Akça O, Şimşek A, et al. Robot-assisted radical perineal prostatectomy: first experience of 15 cases. Turk J Urol 2017;43:476-83.

56. Kaouk JH, Akca O, Zargar H, et al. Descriptive Technique and Initial Results for Robotic Radical Perineal Prostatectomy. Urology 2016;94:129-38.

57. Tuğcu V, Akça O, Şimşek A, et al. Robotic-assisted perineal versus transperitoneal radical prostatectomy: A matchedpair analysis. Turk J Urol 2019;45:265-72.

58. Aboumohamed AA, Hemal AK. Should post-kidney transplant patients with localized prostate cancer be undergoing robotic radical prostatectomy? Int Urol Nephrol 2015;47:643-4.

59. Ouzzane A, Puech P, Lemaitre L, et al. Combined multiparametric MRI and targeted biopsies improve anterior prostate cancer detection, staging, and grading. Urology 2011;78:1356-62.

60. Bott SR, Young MP, Kellett MJ, et al. Anterior prostate cancer: is it more difficult to diagnose? BJU Int 2002;89:886-9.

61. Tay KJ, Villers A, Polascik TJ. Targeted Anterior Gland Focal Therapy-a Novel Treatment Option for a Better 
Defined Disease. Curr Urol Rep 2016;17:69.

62. Villers A, Puech P, Flamand V, et al. Partial Prostatectomy for Anterior Cancer: Short-term Oncologic and Functional Outcomes. Eur Urol 2017;72:333-42.

63. Abdollah F, Jeong W, Dalela D, et al. Menon-precision prostatectomy (MPP): An idea, development, exploration, assessment, long-term follow-up (IDEAL) stage 1 study. Eur Urol Suppl 2019;18:e622.

64. Pathak RA, Hemal AK. Management of low-risk prostate cancer in patients with enlarged glands and lower urinary tract symptoms: robotic total prostatectomy, a novel technique. World J Urol 2019. [Epub ahead of print].

65. Rogers E, Ohori M, Kassabian VS, et al. Salvage Radical Prostatectomy: Outcome Measured by Serum Prostate Specific Antigen Levels. J Urol 1995;153:104-10.

66. Chade DC, Eastham J, Graefen M, et al. Cancer control and functional outcomes of salvage radical prostatectomy for radiation-recurrent prostate cancer: a systematic review of the literature. Eur Urol 2012;61:961-71.

67. Gontero P, Marra G, Alessio P, et al. Salvage Radical Prostatectomy of Recurrent Prostate Cancer: Morbidity and Functional Outcomes from a Large Multicenter Series of Open versus Robotic Approaches. J Urol 2019;202:725-31.

68. Chade DC, Shariat SF, Cronin AM, et al. Salvage Radical Prostatectomy for Radiation-recurrent Prostate Cancer: A Multi-institutional Collaboration. Eur Urol 2011;60:205-10.

69. Bonet X, Ogaya-Pinies G, Woodlief T, et al. Nervesparing in salvage robot-assisted prostatectomy: surgical technique, oncological and functional outcomes at a single high-volume institution. BJU Int 2018;122:837-44.

70. Devos B, Al Hajj Obeid W, Andrianne C, et al. Salvage high-intensity focused ultrasound versus salvage radical prostatectomy for radiation-recurrent prostate cancer: a comparative study of oncological, functional, and toxicity outcomes. World J Urol 2019;37:1507-15.

71. Swanson G, Thompson I, Basler J, et al. Metastatic Prostate Cancer-Does Treatment of the Primary Tumor Matter? J Urol 2006;176:1292-8.

72. Leyh-Bannurah SR, Gazdovich S, Budäus L, et al. Local Therapy Improves Survival in Metastatic Prostate Cancer. Eur Urol 2017;72:118-24.

73. Heidenreich A, Pfister D, Porres D. Cytoreductive Radical Prostatectomy in Patients with Prostate Cancer and Low Volume Skeletal Metastases: Results of a Feasibility and Case-Control Study. J Urol 2015;193:832-8.

74. Gratzke C, Engel J, Stief CG. Role of Radical Prostatectomy in Metastatic Prostate Cancer: Data from the Munich Cancer Registry. Eur Urol 2014;66:602-3.

75. Jang WS, Kim MS, Jeong WS, et al. Does robot-assisted radical prostatectomy benefit patients with prostate cancer and bone oligometastases? BJU Int 2018;121:225-31.

76. Sooriakumaran P, Karnes J, Stief C, et al. A Multiinstitutional Analysis of Perioperative Outcomes in 106 Men Who Underwent Radical Prostatectomy for Distant Metastatic Prostate Cancer at Presentation. Eur Urol 2016;69:788-94.

77. Won ACM, Gurney H, Marx G, et al. Primary treatment of the prostate improves local palliation in men who ultimately develop castrate-resistant prostate cancer. BJU Int 2013;112:E250-5.
Cite this article as: Liu S, Hemal A. Techniques of robotic radical prostatectomy for the management of prostate cancer: which one, when and why. Transl Androl Urol 2020;9(2):906918. doi: 10.21037/tau.2019.09.13 